\title{
Por uma sociologia da economia de cunho etnográfico e histórico \\ Entrevista com Marie France Garcia-Parpet
}

\author{
Elisa Klüger* \\ https://orcid.org/0000-0002-2375-8565 \\ Lilian Verena Hoenigsberg Krohn** \\ https://orcid.org/0000-0003-4986-7783
}

A trajetória da cientista social Marie France Garcia-Parpet é marcada por sucessivos deslocamentos entre a França e o Brasil e por uma combinação das perspectivas analíticas da economia, da sociologia e da antropologia. Garcia-Parpet fez larga parcela de sua formação acadêmica no Brasil, realizando etnografias sobre feiras e mercados no Nordeste que resultaram no mestrado e no doutorado defendidos no Museu Nacional da Universidade Federal do Rio de Janeiro (UFRJ). Tal pesquisa inseria-se em um programa mais amplo de investigação, que buscava estudar as transformações em curso no Nordeste e que era dirigido por seu orientador, Moacir Gracindo Soares Palmeira, antropólogo, doutor em sociologia pela Université Paris v e professor do Museu Nacional ${ }^{1}$. Da equipe de pesquisa inicial participavam também a cientista social Lygia Sigaud, a historiadora argentina Beatriz Maria Alasia de Heredia e os então economistas José Sérgio Leite Lopes e Afrânio Raul Garcia Jr., marido de Marie France. Ao final do projeto, parte do grupo intensificou sua cooperação com a França, reforçando laços com o grupo de pesquisa dirigido por Pierre Bourdieu no Centre de Sociologie Européenne e em uma de suas subdivisões, o Centre de Sociologie de l'Éducation et de la Culture, dirigido por Monique de Saint Martin

* Centro Brasileiro de Análise e Planejamento, São Paulo, Brasil.

** Universidade de São Paulo, São Paulo, Brasil.

1. Os projetos dirigidos por Palmeira sobre o Nordeste foram, em sequência cronológica invertida: "Emprego e mudança socioeconômica no Nordeste”, "Os mercados locais como elemento de mudança numa área de plantation" e "Sistemas de distribuição e estruturas de poder no Nordeste”. Ver Palmeira (1994). 
e Jean-Claude Combessie. Pierre Bourdieu foi decisiva influência na conformação das pesquisas de Garcia-Parpet. Ela teve contato com seus escritos sobre a Argélia ainda no Museu Nacional e posteriormente se alinharia com a rejeição de Bourdieu a categorias autodeclaradas universais do pensamento econômico e em sua adoção da perspectiva etnográfica e análise histórica como vias para apreender as dinâmicas sociais envolvidas na produção da economia ${ }^{2}$.

Atualmente posicionada no Institut National de la Recherche Agronomique (Inra), em Ivry-sur-Seine, Marie France faz, ao lado de Afrânio Garcia Jr., anuais peregrinações ao Brasil, reforçando antigos vínculos de amizade e longas parcerias intelectuais. A formação acadêmica binacional ofereceu a Garcia-Parpet um olhar crítico no que concerne à justificativa de que os fenômenos econômicos poderiam ser explicados socialmente, quando na periferia, visto ser subdesenvolvida, e deveriam ser interpretados de acordo com a pura teoria econômica, quando no centro - tema que discute na entrevista. Tal percepção fez com que assumisse o desafio de conduzir estudos de feiras e mercados na França, e posteriormente em âmbito internacional, constatando a persistente importância de fatores históricos, relações sociais, concepções de mundo dos agentes e jogos de poder para a moldagem dos fenômenos econômicos. Aos estudos empreendidos no Nordeste nos anos 1970 (Garcia-Parpet, 1997; 1984; 1993, pp. 57-72), seguiram-se pesquisas sobre o mercado informatizado de morangos de Fontaines-en-Sologne ${ }^{3}$, região próxima à cidade na qual nasceu; sobre a produção, consumo e certificação dos vinhos franceses, interessada especificamente na mundialização do mercado de vinhos (Garcia-Parpet, 2004, pp. 129-150; 2005 , pp. 63-72; 2007, pp. 37-57; 2014); e mais recentemente estudo acerca dos salóes internacionais de bens simbólicos (Garcia-Parpet, Lecler e Sorá, 2015). A sequência de trabalhos empíricos propiciou, também, a elaboração de artigos baseados em reflexões sobre a concepção e confecção de estudos sociológicos da economia (Duval e Garcia-Parpet, 2012, pp. 13-28; Garcia-Parpet, 2013, pp. 91-117 e pp. 107-127) - termo que argumenta, na entrevista, ser mais adequado do que a corrente denominação sociologia econômica.

Em 26 de março de 2015, Marie France Garcia-Parpet apresentou, no Departamento de Sociologia da Universidade de São Paulo, a conferência “O tempo e o vinho:

2. Para uma reconstrução da trajetória dos pesquisadores do Museu Nacional e contexto da formação acadêmica de Marie France Garcia-Parpet, ver Lopes (2009, pp. 5-8), Palmeira (1994; 2010) e Garcia-Parpet (2014, pp. 181-190).

3. Garcia-Parpet (2002, pp. 196-211).O original em francês data de 1986, posteriormente traduzido para o português e para o inglês. A pesquisa obteve larga consagração e ofereceu subsídios tanto para o desenvolvimento de uma sociologia dos dispositivos, liderada por Michel Callon, quanto para o desenvolvimento de uma sociologia bourdieusiana da economia, com ênfase nos habitus, trajetórias e tomadas de posição dos agentes. 
a construção de um mercado de bem simbólico”. Na ocasião, aceitou gentilmente conceder uma entrevista sobre sua trajetória pessoal e acadêmica e suas visões sobre a "sociologia econômica". A entrevista teve duração de setenta minutos e foi realizada no dia 27 de março, no saguão do hotel no qual estava hospedada em São Paulo, por Elisa Klüger e Lilian Verena Hoenigsberg Krohn, à época pós-graduandas em sociologia. A entrevista foi editada por Klüger e Krohn e revisada por Garcia-Parpet em novembro de 2018 .

Elisa Klüger: Gostariamos de começar a entrevista com uma parte biográfica. Queriamos primeiro que reconstruisse a sua trajetória social e acadêmica. Onde você nasceu? Onde fez os estudos? Quando e como veio para o Brasil pela primeira vez?

Marie-France Garcia-Parpet: Nasci em Bracieux, que para o Brasil seria quase um povoado. Nasci perto do mercado dos morangos que estudei em 1985-86 e fiz os meus estudos secundários em Blois, cidade situada a vinte quilômetros de lá. Depois fiz a minha graduação em Paris, em economia. Quer dizer, fiz a primeira parte em Paris e depois me mudei para Nanterre, porque eu não tinha dinheiro para estudar e os aluguéis já eram muito caros em Paris. Então Nanterre foi uma solução, porque tinha residência universitária. Na sequência eu conheci o Afrânio Garcia Jr. e vim para o Brasil. Quando acabei a minha graduação, portanto, eu morei aqui. Entrei no Museu Nacional em 1970 e fiz antropologia, então na verdade a minha formação foi dupla.

Klüger: Em qual universidade a senhora estudou economia?

Garcia-Parpet: Era na Faculdade de Direito, Economia e Ciências Econômicas até 1968 e a partir de maio de 1968 na Paris X-Nanterre, onde permaneci até 1970. Na minha formação, alguns professores eram marxistas, mas aprendia-se essencialmente economia neoclássica. Acho que foi daí que veio todo o estímulo para fazer sociologia ou antropologia. Eu realmente imaginava fazer economia quando eu estava no ensino secundário, mas esperava outra coisa. Eu considerava os esquemas explicativos extremamente [inadequados] e, portanto, acho que minha gana de discutir com os economistas vem de lá, porque eu me sentia totalmente por fora do esquema que estava sendo ensinado.

Klüger: Você conheceu o Afrânio Garcia Jr. no periodo em que ele esteve na casa do José Sérgio Leite Lopes em Paris?

Garcia-Parpet: Não. O Afrânio já tinha saído da casa deles, porque o físico José Leite 
Lopes já havia voltado. Eu acho que naquela época ele estava [morando] no convento. Para poder pagar a estadia, ele lavava a louça no convento de la Glacière. Ou ele já tinha saído do convento e trabalhava em um banco. Naquele momento eu ganhava a minha vida tomando conta de criança e era bedel nas escolas primárias para me sustentar.

Klüger: Foi nesse periodo também que você conheceu o Moacir Palmeira ou só veio a encontrar com ele posteriormente?

Garcia-Parpet: Eu vim a conhecer o Moacir nessa época. Mas quando o conheci em Paris eu não falava português, então a única coisa que eu me lembro do Moacir é que, escutando ele falar, comecei a distinguir algumas palavras em português. Depois, quando cheguei ao Brasil, ele foi meu professor, eu fiz a revisão da tese dele e acabei entrando nas pesquisas coordenadas por ele. Antes disso conheci, mas não tive nenhuma troca especial.

Klüger: O encontro com ele influenciou a ligação de vocês com o Museu Nacional depois?

Garcia-Parpet: Na verdade eu não conhecia nada do Brasil. Confiei no Afrânio, que me disse: "Olha, o Museu Nacional é o que você tem de melhor a fazer". Eu desembarquei aqui não falando português, quer dizer, tinha estado aqui dois meses e aprendido um pouco. Cheguei ao Brasil acho que no dia 15 de agosto de $1970 \mathrm{e}$ no dia seguinte entrei no Museu, usufruindo de uma bolsa da Fundação Ford. Foi uma coisa horrível, porque eu não sabia falar a língua. A maioria dos alunos era brasileira, mas eu me lembro, inclusive, que tinha alguns argentinos; e os argentinos falavam a língua deles. Quando eu começava a pegar o trem de saber o que estava se falando, aí entrava um argentino e eu ficava desesperada a ponto de ir embora. Além do mais, lidava-se muito com uma literatura sociológica que eu não conhecia, pois vinha da economia. E a literatura era inglesa e em espanhol, portanto foi uma ducha de água fria. A antropologia também era uma coisa nova. Eu me lembro de um texto que expus no curso do Roberto Cardoso, acho que do [Raymond] Firth. Eu achava legal a descrição de todos os objetos. Considerava um passo grande para passar a pensar a economia e para pensar uma outra realidade também. Porque a questão nos cursos era discutir - eu me lembro: o Moacir discutia - se era um sistema feudal, se era capitalismo... E eu mal conhecia o Brasil, só tinha uma ideia do que aprendi na escola, no secundário.

Klüger: E como foi o desafio, neste contexto de adaptação ao pais, de ir fazer etnografia com populaçôes do Nordeste? 
Garcia-Parpet: Isso foi fantástico, porque ali inclusive você começa a conhecer. Eu acho que para qualquer aluno o campo é revelador, porque você está confrontada a uma determinada realidade. Entendo que meu primeiro campo foi importante, porque eu estudei uma feira pequena, uma feira situada em uma usina de açúcar. E a questão dos preços, que é a questão central para a economia, não era o que via lá. A questão era a dominação. Então toda a questão do social e do econômico para mim já foi colocada de antemão naquela primeira pesquisa, que foi muito reveladora.

Klüger: Você percebia algum impacto quando estava no campo do fato de não ser brasileira? Isso abria mais diálogo com as pessoas? Era fonte de algum tipo de dificuldade?

Garcia-Parpet: Havia muita dificuldade, pois os anos 1970 foram um período duro. Para fazer pesquisa naquela época no Nordeste, a gente tomava todas as precauções, porque era ditadura. $\mathrm{O}$ fato de ser uma francesa fazia com que eu tivesse muito medo de aparecer e também de estar fora dos padrões locais. Agora, o que foi muito engraçado é que eu já falava português mais ou menos e tinha um camponês com quem a gente já tinha uma relação mais forte. Foi ele quem indicou todo mundo. $\mathrm{O}$ Afrânio tentava às vezes falar com esse camponês sobre o presidente - por exemplo, perguntar sobre o modelo de representação política -, e o cara não entendia por que ele estava perguntando quem é o presidente... afinal ele era o universitário. Eu sentia muito isso, então eu fazia o papel da mediação. Por ser de fora, eu conseguia retomar as coisas, voltar para algum ponto que ele comentou. "A dona Maria - que era meu nome, porque ali não podia falar meu nome -, ela vem de longe." Eles achavam que eu vinha de ônibus da França, porque não tinham ideia de onde era a França. "Ela entende melhor do que o senhor" ... porque eu tentava. O fato de ser francesa, eu acho que ali eu vivi como uma estratégia de pesquisa.

Klüger: Nas pesquisas do grupo do Moacir Palmeira e da Lygia Sigaud, quais eram as maiores influências teóricas? Havia marxismo, estruturalismo? Já estavam se aproximando do Bourdieu de alguma maneira?

Garcia-Parpet: Estava tudo ali. O próprio Bourdieu saiu do estruturalismo. E o Bourdieu já estava muito presente no trabalho do Moacir.

Klüger: Vocês conheceram o Pierre Bourdieu pessoalmente quando?

Garcia-Parpet: Foi em 1981 ou 1982. Fomos todos - Lygia, Moacir, Afrânio, Beatriz Heredia, Olga Nogueira da Cruz e eu - e apresentamos as pesquisas em um seminário 
organizado pelo Bourdieu em 15 de janeiro de 1982. E o que era interessante era que o Bourdieu na verdade não estava mais lidando com a questão do camponês, que tinha estudado tanto na Argélia quanto em sua aldeia natal. Mas ele nunca deixou de se ligar nessa questão, o que é possível constatar na obra toda. Era uma coisa que estava sempre muito presente na cabeça dele, porque foi dali que partiu, na verdade, toda a originalidade da pesquisa e do pensamento dele. Por exemplo, vendo as estruturas sociais da economia [2000], ele não volta aos textos anteriores, mas começa por reafirmar a importância que essas investigações tiveram na questão da distanciação do pesquisador frente ao objeto escolhido. $O$ fato de ter estudado a sociedade argelina foi importante para pegar a questão da historicidade, do não universalismo das categorias capitalistas. Depois foi a questão do conceito de habitus que vem de lá. A própria noção de capital simbólico, que é central para desenvolver todas as questões em torno da produção artística. E na verdade toda essa questão da denegação da economia vem de lá. Outro aspecto importante é o seu duplo pertencimento. Ele tendo origem camponesa na França e indo para a Argélia, resultou em uma densidade metodológica que teve muito rendimento. Quando voltamos para a França, o Afrânio já tinha acabado o doutorado e foi fazer um pós-doutorado com o Bourdieu (1983-1986). Eu na primeira parte dessa estadia acabei a minha tese e na segunda parte fiz a pesquisa sobre o mercado computadorizado de morangos de Fontaines-en-Sologne.

Klüger: Conversando com o Afrânio, há dois anos, eu me lembro de ele ter mencionado que, quando você escolheu fazer o estudo do mercado de morangos, o Bourdieu havia sugerido que você fosse estudar um mercado moderno em uma região tradicional.

Garcia-Parpet: O Bourdieu estava interessado, mas ele disse: "Olha, para estudar essa questão [de feiras], vai trabalhar com o Chiva”. O Isac Chiva era um antropólogo que foi vice-diretor do laboratório de antropologia do Lévi-Strauss no Collège de France. E o Chiva trabalhava muito sobre essa questão de feiras e foi ele quem me levou a fazer o trabalho na França. Ele disse: "Você fez sua pesquisa no Brasil, agora vamos trabalhar aqui. Eu te financio". Naquela época ele era do Patrimoine Ethnologique. Um dos problemas que eu tinha tido com a minha tese de doutorado [sobre as feiras no agreste paraibano] era o seguinte: eu estava convicta de que o social era mais abrangente que a economia, então o social estaria em qualquer lugar dentro da economia. Quando você olhava para a sociedade periférica, como era o meu caso estudando as feiras do Nordeste, você acabava chovendo no molhado porque todo mundo aceitava que nessas áreas, que não estão no centro do capitalismo, é possível mostrar que tem relação social e está tudo bem, fica tudo no melhor dos mundos. 
Eu já estava cansada disso e sabia que aquilo teoricamente não levava a nada. Outra coisa é quando o próprio Chiva disse: "Olha, o estudo de feira aqui na França está péssimo”. E aí eu pensei: eu, que chego de fora, logo ter um convite de financiamento é porque a coisa está complicada, então eu precisava fazer alguma coisa nova e não podia errar. Enquanto eu estava procurando o que eu ia fazer, a Monique de Saint-Martin conversando comigo disse: "Olha, o Chiva está muito entusiasmado, mas ele não está sozinho no Patrimoine Ethnologique. E para conseguir financiar alguma coisa do Patrimoine tem que ser algo ligado ao campo”. Aí eu pensei: não é possível, lá vou eu repetir estudos no campo. Eu achei aquilo péssimo, estava muito desesperada. Aí me lembro de que um dia fui à biblioteca da École [des Hautes Études en Sciences Sociales] e li justamente o número da revista Études Rurales [1980, v. 78-80] sobre feiras onde tem um artigo que fala desse tipo de mercado que eu estudei ["Le développement des marchés au cadran dans la région du Nord”, de Jean Vaudois]. Quando li o artigo, achei a minha via, porque a impressão que eu tive é que até então não tinha homens e mulheres no artigo, não tinha indivíduos, era uma coisa assim totalmente lisa, fora da história. Aí eu pensei: aqui tem um negócio em perspectiva moderníssima! Não era o campo tradicional, era o campo moderno aonde chegava o capitalismo, onde tinha relações mercantis e uma máquina, o computador para regular as interações. [Mas] ao invés de voltar a esse lugar, situado no norte da França, e tentar uma outra versão, decidi fazer outro campo. Eu sabia do mercado de morangos de Fontaines-en-Sologne porque na minha família por afinidade tem alguns vendedores presentes ali. Então eu sabia um pouco da história desse mercado e dos conflitos que suscitou. Aí também era mais fácil porque eu ia lá para o fim de semana, e foi fantástico porque eles me abriram as portas - eu era da família. Inclusive o meu pai também tinha uma oficina de máquinas agrícolas, e os próprios produtores lembravam disto e consideravam meu pai um cara que os aconselhava. Aí você chega a uma questão que aparece no Bourdieu e que é importante. É que, na verdade, quando você vai ao Nordeste como eu fui, claro que você toma todas as precauções, mas ao mesmo tempo é uma coisa longínqua. Mas ali, em Fontaines, era alguma coisa que eu tinha conhecido, inclusive que eu tinha vivido na pele, o processo relatado por Bourdieu de marginalização, de como uma região mais pobre pode integrar um processo moderno. E quais são as consequências disso para as próprias famílias. Quais os conflitos, como se aceita essa modernidade? E, ao fazer uma pesquisa como essa, você tem uma preocupação, uma certa vigilância, que fica maior porque quando você vai contar a história ali todo mundo tem que encontrar a sua parte. Isso foi uma coisa muito forte, e todo esse trabalho foi facilitado por esses contatos. Agora, para retomar o ponto inicial, o papel do Bourdieu nessa pesquisa foi outro. Eu estava com o Chiva, mas eu expus o esboço da pesquisa, que 
já estava muito adiantado porque tudo avançou muito rápido, e o Bourdieu gostou muito. Ele aderiu totalmente ao projeto e até me financiou, porque o financiamento do patrimônio não tinha saído e o Chiva sumiu totalmente. E, bom, eu tive sorte porque o projeto pôde ser iniciado, pois eu ia para lá para ver a minha família. $\mathrm{O}$ Bourdieu, além de decidir financiar, estava todo animado, inclusive achando que uma das coisas que seria legal fazer adiante seria estudar a bolsa de valores, porque ele tinha exatamente esse princípio segundo o qual era preciso ir ao coração da economia, olhar para onde você pode esperar que não vai encontrar nada de social, quer dizer, onde você supostamente está na economia pura e justamente desmontar isso ao mostrar que em qualquer lugar que você for você sempre vai encontrar o social. Depois tem toda a questão da performatividade, tem a questão dos agentes sociais, a questão da história, havia muita compatibilidade com o que ele pensava, e ele aderiu rapidamente ao projeto quando percebeu que estava indo nessa direção. Deu todo o apoio, depois logo publicou. Então, entre o começo da pesquisa e a publicação, foi muito rápido.

Klüger: E qual foi o efeito de reflexividade de voltar para a sua região e olh ar com outros olhos? Teve uma experiência sociológica e pessoal de releitura daquele lugar?

Garcia-Parpet: Foi muito interessante, porque essa postura de você reler tendo tomado distância dá outra dimensão. Eu acho que foi muito importante.

Klüger: Por que o Bourdieu tem uma narrativa densa dessa volta dele para o local de origem e de como foi encontrar os amigos nessa situação de desencontros de habitus. Você tinha essa impressão também?

Garcia-Parpet: Totalmente. Essa questão do afastamento é uma coisa que me perseguiu bastante, essa questão da ruptura. Eu acho que o Bourdieu conseguiu viver isso de uma maneira muito positiva, mas é uma coisa complicada. Tem um livro, La Place, de 1983, muito importante, de uma escritora chamada Annie Ernaux, que descreve exatamente essa questão. Ela é uma romancista que na verdade é utilizada pelos sociólogos, porque descreve muito como você vai se distanciando da sua classe e como, por exemplo, ela rejeitava os valores, porque você acaba com outros modelos. Então de repente você está fora. Entendeu? Por exemplo, trata-se de uma das coisas que até hoje para mim é muito difícil. As refeições lá são coisas intermináveis. Bom, e se você for lá, você vai ser a parisiense, a intelectual. Tem um sentimento de traição em relação aos teus valores. 
Lilian Verena Hoenigsberg Krohn: Passando aqui à parte mais teórica/metodológica, gostariamos de perguntar sobre essa opção pelo trabalho empirico - que vemos agora que veio de uma antropologia com referencial em pesquisa etnográfica - para fazer uma análise do que seria uma sociologia econômica. Gostaria de saber também como é o trabalho de produzir por meio da prática a teoria dos mercados e se você encontrou alguma forma de resistência justamente por essa opção metodológica diferente.

Garcia-Parpet: Essa direção etnográfica acho que foi dada pela antropologia e talvez seja predominante na maneira de trabalhar, mas a meu ver o trabalho sociológico não pode prescindir disso, tá certo? Porque, veja bem, quando eu fui estudar essa questão da feira no Nordeste do Brasil, na feira que estava situada em uma usina, se eu não fosse entrevistar as pessoas, ver o local, não ia dar certo, entende? Um fato importante, um dado superimportante que eu fui estudar nessa feira, é que eu fui interpelada pela polícia, a polícia do usineiro. E o que isso diz? Que não era um lugar comum. Ao invés de ser um local de abertura, como é dito, a maioria dos textos afirma que o mercado é aberto... Ali era o contrário. Então, veja bem, a meu ver isso é imprescindível, porque eu não podia entrevistar as pessoas. Eu só ia até a feira, e eles convidavam pra casa deles; mas quando eu tentava materializar esse convite, ele não se concretizava. As pessoas fugiam. Foi isso que me deu a entender o que eram aquelas relações sociais e, portanto, o significado dessa feira. Quando eu estudei a questão do vinho, a mesma coisa. Eu acho que a etnografia é superimportante porque atualmente se faz muita coisa na sociologia da economia, mas muitas vezes você esquece os agentes. E na verdade, os agentes não são neutros nessa história toda. Portanto, eu acho que os agentes, a situação... Por exemplo, recentemente a gente fez um texto com Gustavo Sorá e Romain Lecler [Garcia-Parpet, Lecler \& Sorá, 2015] sobre os salões internacionais de bens simbólicos (literatura, filmes e vinho). Fazer a etnografia desses salões não é só uma questão de encontrar as pessoas, pois eles têm inclusive efeitos econômicos. Eles têm efeitos de construção do valor e, na literatura econômica, você nunca percebeu isso como sendo criador de valor. Então, eu acho que a etnografia ela não é a única, mas, como [Clifford] Geertz, eu acho que tem de ser um estudo situado no lugar. E outra coisa: a etnografia não pode dispensar de estar situada em relação a outras coisas. Por exemplo, quando você pega uma praça de mercado, como a própria praça de mercado que eu estudei em Fontaines-en-Sologne, ela mudou. Ela continua existindo no mesmo lugar, mas ela não tem o mesmo significado. Por quê? Porque no intervalo se desenvolveu muito a questão das grandes empresas comerciais, das distribuidoras - do Casino, do Carrefour etc. -, e isso mudou o funcionamento de trocas econômicas. A visão etnográfica é absolutamente necessária, mas não dispensa, de jeito nenhum, um olhar de conjunto. Porque o relacional é uma coisa absolutamente fundamental. 
Krohn: Tinha uma questão de entender se existe dentro do campo acadêmico, mais especificamente na sociologia econômica, uma resistência a essa forma de estudo.

Garcia-Parpet: É difícil de dizer, mas acho que há uma ideia de que a teoria está em outro lugar. E a etnografia continua tendo um status menor dentro da sociologia em relação à teoria. Eu acho que justamente é a etnografia que lhe permite falar a partir de outro patamar, que talvez não seja o mais conhecido, mas que em todo caso considero imprescindível.

Krohn: Uma curiosidade, pensando no mercado de morangos, écomo se realiza a escolha dos mercados a estudar. O vinho, as feiras culturais...

Garcia-Parpet: No caso do morango eu expliquei. Reparem, por exemplo, alguns comentários sobre o mercado dos morangos. Algumas pessoas percebem que ali você desmonta a teoria econômica; enfim, mostra para a teoria econômica que o mercado está embutido nas relações sociais, com modelos econômicos etc. E outro diz: É um estudo de caso, certo? O que é um problema para mim, porque de fato é um estudo de caso. É uma coisa pequena. Inclusive, para procurar, se você vai ao lugar, terá dificuldade, porque é no campo. Mas, ao mesmo tempo, é uma coisa que revela. É como se o objeto teórico tivesse relação com o tamanho da população, por ser micro, por ser macro. Na verdade, não é bem assim. Quando eu fui estudar o vinho, tinha essa questão, justamente para dialogar com os economistas, de como há bens com vários valores. E a mundialização, era justamente para passar do mercado localizado a um mercado muito mais amplo. Permite ver que essa construção, seja no nível local, uma coisa mini, pontual, seja no nível dos mecanismos de mercado como entendem os economistas, você sempre tem que ir além da questão dos preços. Então, sempre tem que ver as relações de força, a questão dos valores que estão em jogo. Tanto do ponto de vista dos produtores quanto dos consumidores. Era essa passagem que eu queria focalizar, para dar outra dimensão.

Krohn: Nesse caso tem a preocupação de unir as várias pontas do processo produtivo. Você cobre o estudo dos produtores, mas entra na questão do consumo, da prescrição, mas como é que você costura toda essa informação sem cair em um mecanicismo, em uma homologia automática?

Garcia-Parpet: É por isso que você não pode usar categorias genéricas. Há uma recomposição das concepções da produção que mudam com o tempo. Você não consegue explicar utilizando só categorias como, por exemplo, "o produtor", “o 
agricultor". Você sempre deve situar as pessoas historicamente, do ponto de vista de um ciclo de vida, do ponto de vista de um país, de uma concepção do consumo ou da atividade. E você vê que muda. Se você não vai ao detalhe dessas coisas, fica genérico: uma homologia entre os produtores e os consumidores. E daí? Então o que acontece quando isso não ocorre, isso que é importante analisar.

Krohn: Pensando os mercados estudados, de morango e de vinho, qual é o traço comum que você encontra, sendo que um é local e o outro internacional? Tem alguma generalidade possivel de traçar?

Garcia-Parpet: O [Georg] Simmel diz que na verdade o mercado é um conflito indireto. Para você entender o que se passa em um mercado, você tem que sair do mercado. Porque uma das coisas superimportantes, na verdade, é que as pessoas entram no mercado com um esquema, uma posição econômico-social. Portanto, a maneira como eles vão ter que agir no mercado depende não do mercado, depende de coisas que às vezes estão muito longe desse feixe de relações. Por exemplo, nesse caso do vinho, tem produtores para os quais existe um salão que é muito importante, o Salon des Vins de Loire. Mas o que é interessante é que produtores que tinham uma produção muito conhecida às vezes não percebem, pela história deles, que o Salon permite dar um salto na comercialização pela visibilidade que cria aos viticultores. Uns falam: "Eu não tenho tamanho para entrar", "Eu não posso". Mas você vê que ele não tem o conhecimento cultural para saber qual é o efeito disso. E como é que você explica isso? Ele está em uma geração anterior, em um espaço social... ele pode estar no mesmo mercado, cultivando as mesmas uvas, mas ele não percebe onde estão as coisas mais relevantes. Então, se você não pegar isso, você não entende as situações sociais com as quais todos estão confrontados. Eu adoro aquele texto do Geertz, Le Souk de Sefou [Geertz, Geertz e Rosen, 1979], mas tem uma coisa que limita muito, que na verdade você vê poucos indivíduos a chegar com a cabeça feita de uma determinada maneira. Isso acho que o Bourdieu pega muito bem nos estudos da Argélia. Como é que a inserção das pessoas no mercado de trabalho depende de onde elas vêm. Se elas se entendem como desempregadas ou não, por exemplo... às vezes é a mesma situação quando você olha para o dado objetivo, só que tem um passado que te faz ler, que te dá uma capacidade, ou não, de você conseguir se inserir estando nessa situação. Então, é isso que é a chave da análise.

Klüger: Eu lembro que Neil Fligstein, no seu curso de sociologia econômica em Berkeley, falava bastante sobre as concepções de controle e sobre como as pessoas evitavam concorrência dentro dos mercados, principalmente pela diferenciação dos produtos como 
uma estratégia de sobrevivência por todas as partes envolvidas. Porque, se fosse a pura concorrência pelo preço no mercado, haveria menos espaço. Olhando para o mercado do vinho, há uma percepção de que as pessoas vão se inserindo em nichos diferentes e sobrevivendo dessa maneira. Como isso aparecia para você, especificamente a questão da concorrência entre os produtores?

Garcia-Parpet: No vinho, aí o Fligstein está inteirinho. O caso pega o Fligstein de duas maneiras: pega a questão do Estado - o estado não entra tão somente como um árbitro que vai lá... Aquela questão do parlamento da III República que diz: "olha, este é o modelo que a gente está valorizando", aquilo tem um efeito devastador sobre os outros porque, quando você está numa área a centenas de metros de diferença, alguns são considerados vinhos nobres e os outros não. Tanto que tem todo um mercado negro, vamos dizer assim, inclusive porque existem arbitrariedades e jogos de poder nos quais você desenha os limites. Às vezes há uma falta de percepção do que está em jogo que exclui uma parte. E também tem o que o Fligstein fala da questão da concepção do mundo, que não está muito desenvolvida no livro, mas que no caso do vinho fica muito patente, porque, na verdade, é um conjunto de valores que passa por uma concepção regionalista, específica, de uma determinada época, por uma maneira de julgar também... É uma construção que se fez na história. Tanto que, quando eu comecei a trabalhar com vinho, não fui trabalhar com os vinhos de Bordeaux por conta disso. Você tem que ir tão longe na história, mas a história está ali. Além disso, o próprio indivíduo francês é um consumidor que conhece o vinho - claro que há diferenças no conhecimento. Por exemplo, na minha casa, o meu pai era um pequeno artesão, não se bebia vinho de Bordeaux, mas todo mundo sabia que o Bordeaux era o top. Então tem uma construção que vai muito longe. Eu reli várias vezes o Fligstein pra achar onde que ele contava essa história. Eu não achei nos escritos dele, mas a ideia era muito boa, e eu tentei, justamente nesse produto, eu achei que era muito interessante. Estou pensando também que uma maneira de você conceber um produto pode tentar descartar outro. Estou me lembrando do texto dos italianos Davide Ravasi, Violina Rindova e Ileana Stigliani [2011], numa coletânea organizada pelo [Jens] Beckert. É um texto interessante, em especial uma passagem sobre a construção das vespas, essas motocas. Você que pensa que a motoca é um veículo de metal, sem mais. Não, para construir as motocas, os designers voltam ao passado. Porque a motoca foi um símbolo de liberdade, de independência, nos anos 1960. As motocas produzidas hoje, apesar de terem mudado de design, procuram manter alguma coisa, desse não sei o quê. A gente pensa, inclusive, que a indústria automobilística é uma coisa mais [material]... mas tem museus, todos os designers que entram na fábrica têm que passar por eles para integrar, de certa maneira, um 
estilo de vida, os valores, essa questão, por exemplo, da liberdade e da independência da juventude dos anos 1960.

Krohn: Pensando nessa questão do Fligstein, das concepções de controle, muitas vezes quando ele coloca isso nos mercados, muitas vezes a mudança vem de fora. Pensando nesse processo do surgimento de novas disposições de agência, de novos segmentos dentro do mercado, como se dá a mudança quando se tem uma visão tão assentada de como o produto é composto? Pensando também no caso da prescrição do vinho.

Garcia-Parpet: No caso do vinho, você tem que pegar ao mesmo tempo a etnografia e a estrutura. Porque o que desbalanceou o mercado foi que a estrutura em que está imerso mudou. Há um jogo entre as coisas miúdas que você vê, os agentes com toda uma concepção do mundo, o consumo..., mas no próprio campo da enologia, você não consegue entender as mudanças sem olhar para as transformações que vêm de fora. Por isso que você tem que pegar a questão pelos dois lados, o macro e o micro, sendo que o micro está se inserindo dentro de uma estrutura determinada, e isso é fundamental.

Klüger: Que outros autores da sociologia econômica, atualmente, são ao mesmo tempo referências, importantes pessoas para diálogo para o seu trabalho? Ou como se posiciona em relação ao Michel Callon, à Marion Fourcade e outras pessoas em áreas próximas?

Garcia-Parpet: Marion tem uns trabalhos ótimos. Eu acho que é uma pessoa que consegue fazer essa introdução de dimensões do sociológico. O trabalho dela sobre a avaliação da natureza nos Estados Unidos e na França através do litígio em torno do naufrágio de navios é lindo [Fourcade, 2011, pp. 1721-1777]. Os textos de Michel Callon trouxeram reflexões importantes, em particular ao demonstrar que a economia se baseava menos em constatações de fatos externos aos modelos do que no uso de modelos para dar vida a novas modalidades de mercados. Talvez eu me pergunte se, na questão da performatividade, que deu origem a tantos trabalhos interessantes, ele não poderia ter situado mais precisamente as características sociais e as condições históricas em que os agentes envolvidos produziram suas inovações.

Klüger: Além desses mencionados, quem seriam outras pessoas com as quais mantém diálogo atualmente?

Garcia-Parpet: Tem um monte de pessoas que fazem trabalhos ótimos, além de meus amigos do Museu, como José Sérgio Leite Lopes e Beatriz Heredia, que 
infelizmente nos deixou, ou de Sérgio Pereira Leite do Centro de Pós-Graduação de Ciências Sociais em Desenvolvimento, Agricultura e Sociedade (CPDA); tem o Federico Neiburg, que é uma pessoa excelente. Roberto Grün abriu um enorme campo de trabalho sobre finanças em conjunto com seus orientados. Aqui em São Paulo, Nadya Guimaraes lidera um grupo muito dinâmico. Sem falar em parceiros na França como Julien Duval, ou Odile Henri, e outros colegas do Centre de Sociologie Européenne; ou ainda os caminhos inovadores propostos por Luc Boltanski desde o Novo espírito do capitalismo. E reler o Bourdieu sempre é algo que dá um gás importante. E outro ponto importante: vamos acabar com a divisão entre subdisciplinas, ao falar de sociologia e não de sociologia econômica. Porque eu acho que o perigo é tomar a sociologia "da economia" como algo definido "a priori", faço questão do termo "sociologia de", pois sociologia econômica é uma maneira de dar primazia ao econômico. Eu tenho muito medo de uma separação dessas disciplinas. Na verdade, quando eu comecei a trabalhar, não havia esse termo sociologia econômica, eu fazia sociologia e antropologia social. Eu lamento isso porque, ao gerar medo de entrar nos meandros dos indivíduos, eu fico com a sensação, muitas vezes, de ler coisas vazias. Acho que é uma gaiola que limita a riqueza da abordagem. Eu sei que é muita pretensão, e os economistas ficam irados porque a sociologia parece imperialista indo para o domínio dos economistas, mas ao mesmo tempo não dá, por exemplo, para não pensar em termos de performatividade dos modelos adotados na evolução dos mercados. Isso ficou provado em vários âmbitos.

Klüger: Uma última perguntinha: queriamos saber que direções a sua pesquisa provavelmente tomará nos próximos tempos. O que você está pensando em trabalhar?

Garcia-Parpet: Ultimamente eu estou trabalhando a questão da patrimonialização dos bens. Fiz um campo sobre Slow Food e ultimamente sobre a valorização da cachaça no Brasil. Quero também retomar os diferentes trabalhos mencionados aqui e sistematizá-los de maneira a evidenciar os pontos teóricos.

\section{Klüger: Superobrigada!}

Garcia-Parpet: Muito obrigada a vocês! 
Duval, Julien \& Garcia-Parpet, Marie-France. (2012), "Les enjeux symboliques des échanges économiques”. Revue Française de Socio-Économie, 10 (2): 13-28. Disponível em https:// www.cairn.info/revue-francaise-de-socio-economie-2012-2-page-13.htm.

FourCADE, Marion. (May 2011), "Cents and sensibility: economic valuation and the nature of "nature". American Journal of Sociology, 116 (6): 1721-1777. Disponível em https://www. jstor.org/stable/10.1086/659640?seq=1\#metadata_info_tab_contents.

Garcia-Parpet, Marie-France. (2013), "A sociologia da economia de Pierre Bourdieu”. Sociologia e Antropologia, 3 (5): 91-117. Disponível em http://www.scielo.br/scielo. php?pid=S2238-38752013000500091\&script $=$ sci_abstract\&tlng=pt.

Garcia-Parpet, Marie France. (2014), "Entretien avec Marie-France Garcia-Parpet, autour de la sociologie économique, avec Pierre Bourdieu réalise par Hélène Ducourant et Fabien Eloire”. Revue Française de Socio-Économie, 13 (1): 181-190. Disponível em https://www. cairn-int.info/article-E_RFSE_013_0181--interview-with-marie-france-garcia.htm.

Garcia-Parpet, Marie-France. (1993), "Espace du marché et mode de domination”. Études Rurales, 131-132:57-72. Disponível em https://www.persee.fr/doc/rural_0014-2182_1993_ num_131_1_3431.

Garcia-PArpet, Marie France. (1984), Feira e trabalhadores rurais: as feiras do Brejo e do Agreste Paraibano. Rio de Janeiro, tese de doutorado em antropologia social, Museu Nacional/ Universidade Federal do Rio de Janeiro.

Garcia-Parpet, Marie-France. (2014), "French biodynamic viticulture: militancy or market niche?". In: Counihan, Carole \& Siniscalchi, Valeria. Food activism: agency, democracy and economy. Londres, Bloomsbury.

Garcia-Parpet, Marie France. (2005), "Le Salon des vins de Loire: convivialité et vocation internationale". Ethnologie Française, 35: 63-72. Disponível em https://www.cairn.info/ revue-ethnologie-francaise-2005-1-page-63.htm.

Garcia-Parpet, Marie-France. (2014), "Marché, rationalité et faits sociaux totaux: Pierre Bourdieu et l'économie". Revue Française de Socio-Économie, 13 (1): 107-127. Disponível em https://www.cairn.info/revue-francaise-de-socio-economie-2014-1-page-107.html.

Garcia-PArpet, Marie-France. (2007), "Mondialisation et transformations du monde viticole: processus de reclassement des vins du Languedoc-Roussillon”. Sociétés Contemporaines, 68 (4): 37-57. Disponível em https://www.cairn.info/revue-societes-contemporaines-2007-4-page-37.htm?contenu=resume.

Garcia-Parpet, Marie-France. (2004), “Mundialização dos mercados e padrões de qualidade: vinho, o modelo francês em questão”. Tempo Social, 16 (2): 129-150. Disponível em http:// www.scielo.br/scielo.php?pid=S0103-20702004000200006\&script=sci_abstract\&tlng=pt.

Garcia-Parpet, Marie France. (1997), O Bacurau: étude de cas d'un marché situé dans une 
usina du Nord-Est du Brésil. Rio de Janeiro, dissertação de mestrado em antropologia social, Museu Nacional/Universidade Federal do Rio de Janeiro.

Garcia-Parpet, Marie France. ([1986] 2002), “Representações científicas e práticas mercantis camponesas”. Raizes, 21 (2): 196-211. Disponível em http://revistas.ufcg.edu.br/raizes/ artigos/Artigo_21.pdf.

Garcia-Parpet, Marie France; Lecler, Romain \& SorÁ, Gustavo. (2015), “Foires, salons et marchés internationaux. Circulation des biens symboliques et mondialisation des places marchandes". In : Guide de l'enquête global en sciences sociales. Paris, CNRS.

Geertz, Clifford. (2003), Le souk de Sefrou: sur l'économie du bazar. Trad. Daniel Cefaï. Saint-Denis, Bouchene.

Geertz, Clifford; Geertz, Hildred \& Rosen, Lawrence. (1979), Meaning and order in Moroccan society: three essays in cultural analysis. Cambridge, Cambridge University Press.

Lopes, José Sérgio Leite. (2009), “Lygia Sigaud (1945-2009)”. Revista Brasileira de Ciências Sociais, 24 (71): 5-8. Disponível em http://www.scielo.br/scielo.php?script=sci_arttext\& pid=S0102-69092009000300001.

Palmeira, Moacir Gracindo. (1994), Memorial do candidato. Rio de Janeiro, Museu Nacional da UFRJ.

Palmeira, Moacir Gracindo. (2010), Moacir Palmeira depoimento. Rio de Janeiro, CPdoc/ FGV; LAU/IFCS/UFRJ; ISCTE/IUL. Disponível em https://cpdoc.fgv.br/cientistassociais/ moacirpalmeira.

RaVasi, Davide; Rindova, Violina; Stigliani, Ileana. (2011), “Valuing products as cultural goods: framework and empirical illustration”. In: BECKERT, Jens. The worth of goods: valuation and pricing in the Economy. Oxford, Oxford University Press.

Texto recebido em 4/3/2019 e aprovado em 2/4/2019.

DOI: $10.11606 / 0103-2070 . t s .2019 .155376$

Elisa KLÜger é pesquisadora do Programa Internacional de Pós-doutorado do Centro Brasileiro de Análise e Planejamento, Cebrap, e visiting postdoctoral research associate na Princeton University (Bolsista Fapesp processos 2017/13937-1 e 2018/09487-7).E-mail: elisa.kluger@gmail.com. Lilian Verena Hoenigsberg Krohn é mestre em sociologia pelo Programa de Pós-graduação em Sociologia da Universidade de São Paulo. E-mail: lilianvhk@gmail.com.

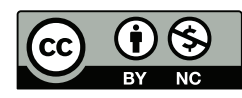

